\title{
Is there a non-present teaching proposal for Methodology in Health?
}

Presently, the consensus in the Brazilian academic community is that Higher Education Institutions should associate the traditional teaching practices to elements that develop critical-reflexive thinking in the students, allowing, through a real world perspective, the concomitant detection of the problems affecting them and adoption of tools that may lead to measures for solving these problems. Thus, there is the need of an effective and efficient Method to achieve such aims.

A Method is defined as the way of performing an operation - doing, acting or knowing - to achieve a previously determined purpose. Logic defines Method as an "art of well displaying a sequence of several thoughts either to find the true when we ignore it or to prove it when we already know it". Due to its complexity, Method is understood as a discipline of knowledge, named Methodology.

Methodology is the study of means or methods to investigate concrete thinking as well as true thinking and tries to differentiate what is true from what is not true, real from fiction. In the academic world, to make science is important for everyone as it results in discoveries and inventions. The method represents thus a way of thinking to reach the nature of a certain problem, either to study or to explain it.

In view of the importance of high-quality Methodology teaching and its lack in most of the Brazilian Schools, a pioneer initiative was done by a group of researchers from São Paulo State University - UNESP and Federal University of São Paulo - UNIFESP, supported by The Coordination for the Improvement of Higher Education Personnel - CAPES.

This partnership led to the first sensu stricto Graduate Discipline taught in a non-present manner. It is named Applied Scientific Research Methodology and Evaluation in Health Sciences [Metodologia de Pesquisa Científica Aplicada e Avaliação em Ciências da Saúde], directed to students from renowned Master's and PhD Programs, and deals with: Health-disease process, Scientific investigation, Experimental designs, Systematic review and meta-analysis, Economy in Health, Scientific writing and Critical evaluation of papers on health. One of its greatest merits is the reflection on the knowledge inconstancy as it allows the comprehension of the man's needs to ask and answer relative to proposed doubts, aiming at the interpretation and explanation of reality, things and phenomena.

In this sense, the knowledge we judge to be valid today can be refuted tomorrow, constituting a fantastic aspect translated into its non-conclusion and into a provisional idea. Debates and the deconstruction of these ideas may become necessary, making such attitude inevitable.

Support and realization: Graduation Course in Tropical Diseases of Botucatu Medical School - UNESP, Center for the Studies of Venoms and Venomous Animals of UNESP CEVAP and Federal University of São Paulo - UNIFESP.

Further information: www.cevap.com.br

\section{CORRESPONDENCE TO:}

PROF. DR. RUI SEABRA FERREIRA JUNIOR, Centro de Estudos de Venenos e Animais Peçonhentos da UNESP - CEVAP, Fazenda Experimental Lageado, Rua José Barbosa de Barros, 1780, 18610-307, Botucatu, SP, Brasil. Phone/Fax: 5514 3814 5555, 551438117241 and 55143814 5446. Email: rseabra@cevap.org.br. 